\title{
THE EFFLUX OF LABOUR FROM AGRICULTURE IN EUROPE, ESPECIALLY FOR THE E.E.C.-COUNTRIES ${ }^{1}$ )
}

\author{
A. MARIS
}

Agricultural Economics Research Institute, The Hague, The Netherlands

\section{INTRODUCTION : THE PROBLEM INVOLVED}

After European man no longer had to go out hunting in order to live and had also said farewell to the nomadic life, he chose a fixed abode for himself, where he could provide for his needs by tilling the fields and keeping livestock. This more or less civilized way of life - civilized when compared with the hunter's and nomad's existence of former times - was in itself undoubtedly one of the effects of the increase in population. Nevertheless, one can say that upto the end of the 18th century Europe remained a comparatively sparsely populated continent.

In predominantly agrarian countries the son's profession in life is determined by the father's. Actually, this is only to be expected-jobs outside farming are scarce, so that the farmer's sons have no choice but to become farmers themselves. There is another reason as well, however. In less-developed areas the average span of live is short and the percentage of productive workers low. Education and training and choosing another profession are luxeries that cannot be afforded - the children must help their fathers with the farmwork as soon as possible. Naturally, under such circumstances there is no very great inclination to make large investments in manpower.

We are concerned here with closely-knit communities organized on traditional lives, where everything passes down from father to son and where there is no need and no inducement of any kind to abandon this ancient system.

Europe, too, lived for a long period in the peace of a static society of this nature and it was not until the 18th century that it was awakened by the magic wand of industrial technique. The stormy development that ensumed from this and which has still not come to a halt - indeed, it has just entered upon a new phase - shook society, once so solid and secure, to its foundations. Man is still looking for new ways of maintaining himself and adapting himself to this technical development and economic growth, which have taken place on a hitherto unheard of scale and have changed the face of the earth completely.|

The most remarkable feature about the Europe of the 19th and 20th centuries is the marked increase in the number of occupations and especially in their greater differentiation. Upto the end of the 18th century, Europe was a comparatively thinly populated continent where, apart from a little trade and industry, the population was engaged mainly in farming. Whereas prior to the change in economic structure we refer to as the Industrial Revolution,

1) Received for publication October 4, 1958. 
$50-80 \%$ of the employed population was engaged in farming, in several countries this figure has now declined to less than $20 \%$. England has gone the furthest in this respect; with only about $6 \%$ of the employed population working on the farms, she occupies a unique position. On the other hand, there are still some countries in Europe where a very high percentage of the population is engaged in agriculture. Rumania, Bulgaria and Yugoslavia, for example, with more than $60 \%$; while Spain and Italy, resp. with about $35 \%$ and $54 \%$, are both still a long way from arriving at the stage of development reached by Western Europe. This industrial revolution has been accompanied by an enormous expansion in the population. In the past 150 years the population of Europe (excluding the U.S.S.R.) has risen from 140 to over 400 million. The corresponding figures for the six countries of the European Economic Community were 75 million (including the whole of Germany) and 160 million (including Western Germany only).

Naturally, this increase in the number of occupations and in the population did not take place at the same rate everywhere and at all times; it would, indeed, have been far more a matter for surprise if this evolutionary process had developed evenly and harmoniously throughout. An important safely valve for the tension resulting from the lack of equilibrium between people and occupations was emigration. For Europe it was extremely important, particularly emigration to North and South America. In the period 1821-1932 about 54 million Europeans emigrated, no less than 34 million of them going to the United States. Until 1880, 85\% of the European emigrants came from Western Europe, while in the period 1910-1914 the corresponding figure was only $30 \%$. The relevant percentages for Southern and Eastern Europe were $15 \%$ and $70 \%$ respectively. This shift was due in part to the fall-off in the expansion of the population in Western Europe as a result of declining birthrates, and in part to the progressive rise in the level of welfare in this region of Europe, which meant that there was far less inducement to emigrate.

It will be little cause for surprise either that migration within national frontiers - i.e. mainly the flow of the rural population from farming to nonagricultural occupations - did not always take place to the desired extent and at the desired juncture. For century after century farming had been carried on small farms, employing a highly primitive technique and existing within the confines of communities which were entirely sealed-off - economically, socially and culturally - from the outside world, and there can be no doubt that farming has still not adapted itself in sufficient measure to the possibilities which technical and economic development has to offer, such possibilities as improved methods of crop-cultivation, but, above all, possibilities of mechanization and of finding occupations outside agriculture. In fact, many countries are still in the midst of an agrarian revolution: the agricultural population is still declining, mechanization increasing and a beginning has only just been made with the introduction of the necessary improvements in the structure of the farming industry.

It is not, perhaps, going too far to say that one of the principal factors in the economic growth mentioned above was - and still is as regards the 
changes that are necessary in the structure of farming - the increase in the productivity of labour in agriculture, accompanied by large-scale migration from farming among the younger age-groups. For greater productivity of labour in agriculture means that more food is produced, with the result that hands become free for the production of industrial goods. On the one hand, therefore, Europe's industrial expansion would not have been possible without the exodus of some labour from agriculture, while on the other hand agriculture can only maintain its position in a country experiencing large-scale economic expansion by shedding part of its labour force and passing it on to industry. Originally, one man could produce sufficient food for his own family, while nowadays there are countries where one agricultural worker can produce sufficient food for eight families - the best farmers producing considerable more. This means that the farming population in these countries could decline to as little as $12 \%$ of the total population and probably - taking into account the results the best farmers now achieve - to appreciably less than $10 \%$. A country like Denmark has already reached this stage ${ }^{1}$ ). There the farm workers' productive capacity is sufficient to feed eight families; the number of persons employed in agriculture per 100 ha of farmland being about 10 .

If one reviews the figures relating to employment in farming in the countries of Europe, one is forced to the conclusion that a great deal of labour could still leave agriculture. The first requirement for this is that large numbers of people should be willing to say farewell to farming. Then they should show sufficient occupational skill for employment in industry and - a factor of equal importance - the aptitude to adapt themselves to, and feel at home in, an entirely different environment. The prerequisite for all this is, it goes without saying, that the agricultural population should be prepared to introduce a complete modernization of the whole apparatus of farm production, bringing it into line with the present state of technical development. This is easily said; but it should be realized that it means making enormous demands on the farming community. Put briefly, it amounts to the complete economic, social and cultural opening-up of the countryside and will consequently require a willingness to break with the ancient and deeply-rooted tradition of "like father, like son" mentioned above.

It is against this background that we shall have to consider the question of the gradual outflow of labour from agriculture. In the following paragraphs a number of figures will first be given with regard to the numbers employed in agriculture and the number of boys up to the age of 14 in farming families. To avoid an excess of detail - and in view of the absence of all the information required - these figures will relate to the six countries of the European Economic Community and to a few countries who occupy a salient position as far as our subject is concerned, that is to say Yugoslavia, England and Denmark. Yugoslavia, as an example of a European country which is still a pre-dominantly agricultural country; England as the country where the size of the farming population has declined to the greatest extent; and Denmark as a country that may, perhaps, serve as an example for many others, com-

1) It should be noted that $60 \%$ of the total of agricultural production is exported. 
bining, as it does, intensive agricultural production with a comparatively small agricultural labour force.

All these figures are very approximate only. In order to obtain a complete picture of employment in agriculture and the required outflow of labour from farming, more particulars would be necessary and would need to be grouped according to type of agricultural undertaking, size and region. An enquiry of this nature has, in fact, been carried out in the Netherlands and some of the results obtained will soon be published. This introduction will end with a number of conclusions.

\section{The agricultural LABour FORCE: THE PRESENT SITUATION AND THE FUTURE}

In the preceding pages we have put forward the view that if the level of welfare in agriculture is not to decline below that in other branches of industry, it will be necessary to bring about an increase in the productivity of labour. This can be achieved by increasing the material yield per acre and per animal and by reducing the amount of labour employed. We shall not be going into the first point any further here. The second brings us to the question of the gradual outflow of labour from agriculture that will be required. Table 1 demonstrates the great variation in the numbers employed in agriculture among the different countries of Europe. More detailed figures would show that there are similar wide divergencies from region to region within each country as well. One might, for instance, compare the situation in the north of Germany and of France with the situation in the south of these countries. As two highly important factors producing these differences, we must quote the size of the farms and the degree of mechanization (together with the farming methods employed).

When referring to the matter of size, we think immediately of the problem of the small farmer, one of the weak spots in European agriculture. On the small farms the amount of labour employed per unit of cultivated land is approximately four times as much as that on the larger farms, and is so for more or less the same type of farm. Various inquiries made have shown that the employment by these small farms of a relatively large amount of labour is accompanied by a low level of productivity and low per capita income. The reason for this lies in the fact that on these farms the supply of labour may be insufficiently adapted to the demand - the amount of family labour is, after all, determined by the number in the family and the result is a constant latent surplus of labour on such farms. The figures for the number of farms (see table 1) of less than 10 ha shows that in agriculture in Europe this problem is of great importance quantitatively too. Its solution - which, in our view, must be found by reducing the number of small farms - could, therefore, make an important contribution towards raising labour productivity in farming in Europe. The fact that the number of small farms has decreased appreciably in some countries in recent years shows that the matter is occupying people's attention. In various countries a conscious policy designed to bring about a change in the structure of the farming industry is now being pursued in addition to price policy, such a policy linking up with a natural process of change. As regards the second factor, the degree of mechanization, the figures in table 1 provide a picture of the situation. The differences still appear to be very great and consequently the possibilities, too. 


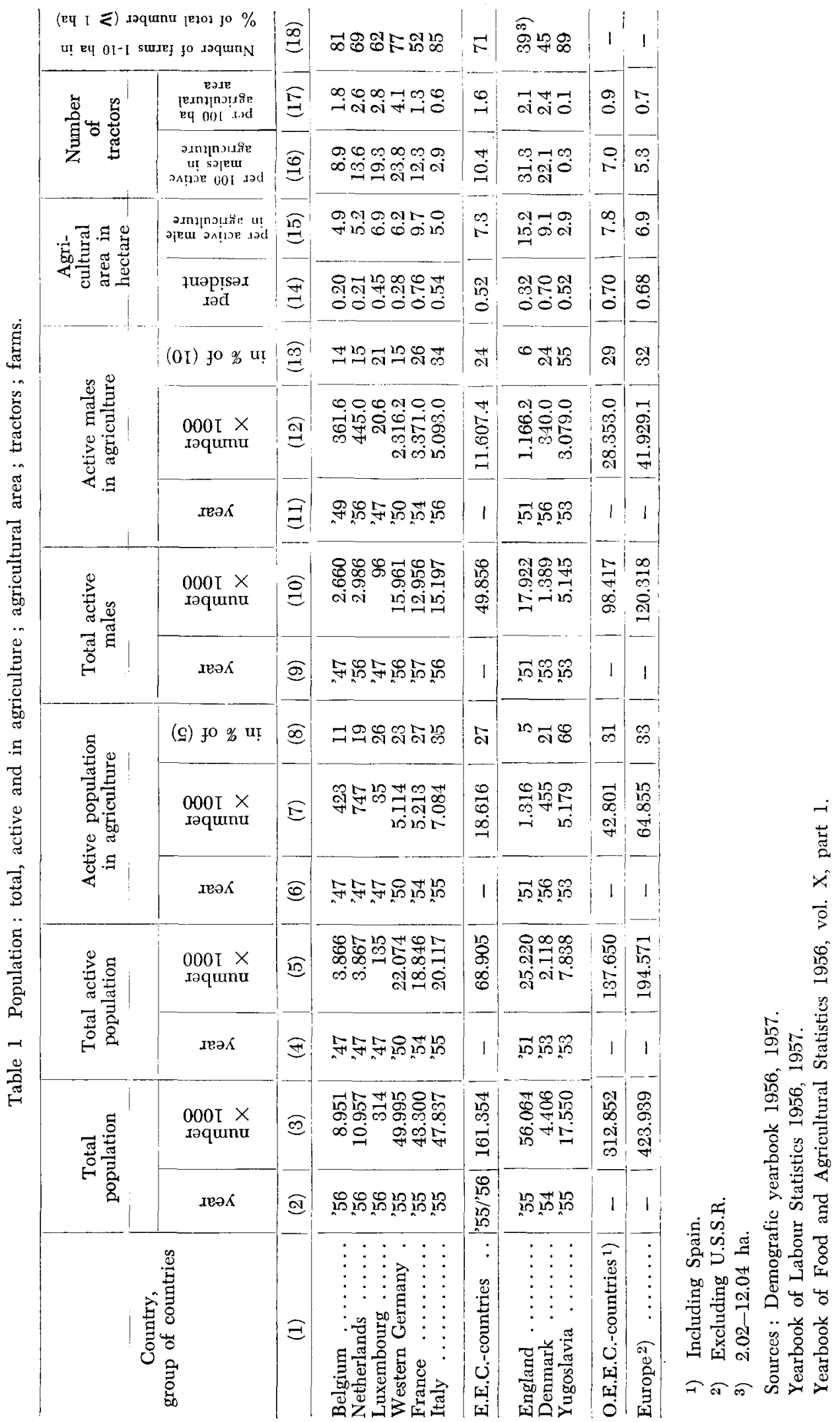




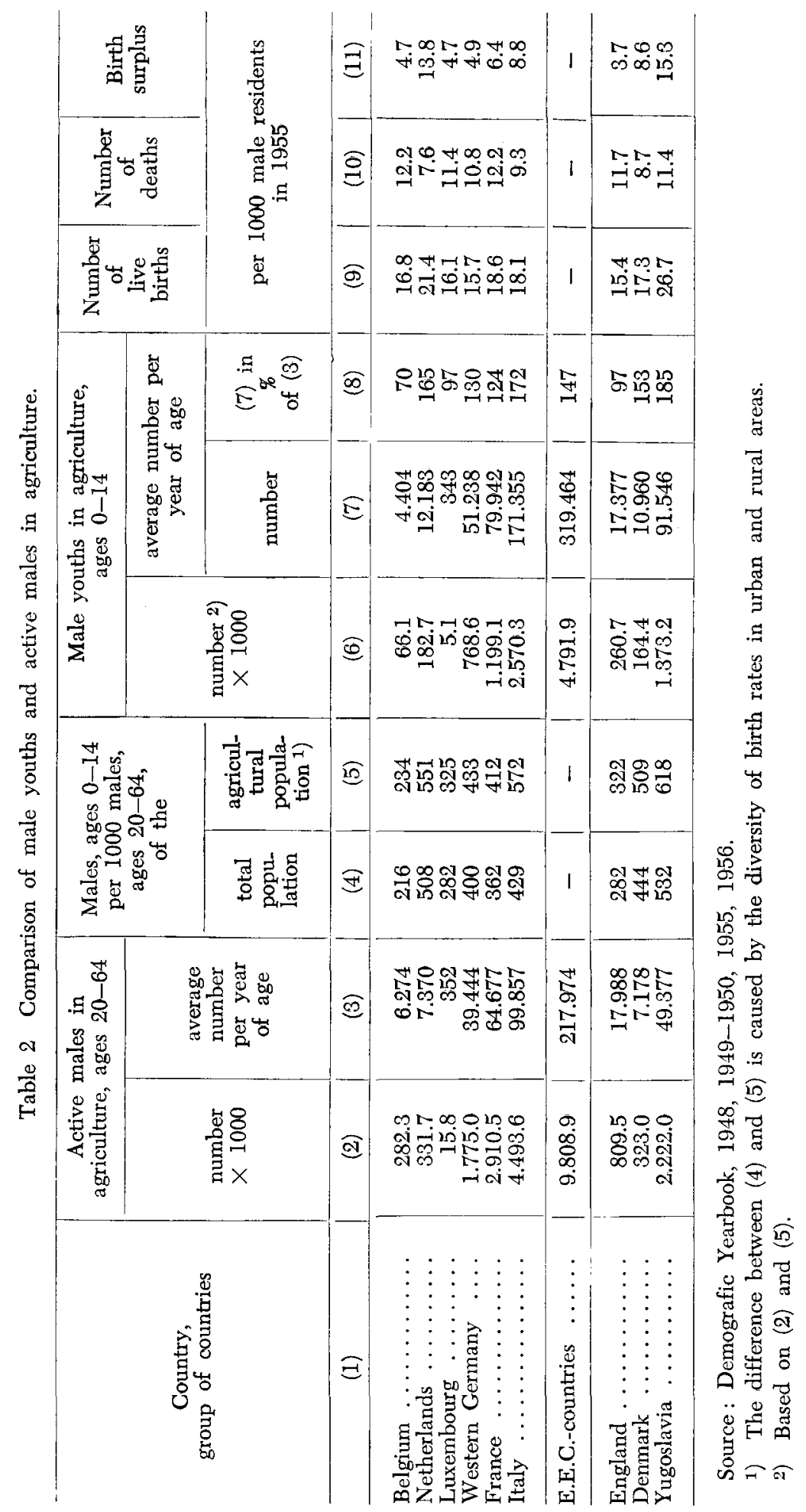


The raising of the level of labour productivity in European farming which is so highly desirable will have, therefore, to come about by reducing the numbers employed in agriculture, among other things, and this reduction will be made possible mainly by mechanization and by improving the conditions of production.

An important question is the following : what proportions will this reduction in the amount of labour employed in agriculture assume in the next fifteen years? In view of the fairly slight degree of mechanization so far introduced in many countries of Europe and the large number of under-sized family farms, the existing possibilities seem great to us. A 30 to $50 \%$ reduction in the number of farms of less than 10 ha - whereby, in this size group, the area of cultivated land per worker could be more or less doubled - must certainly be possible. If one also takes the possibility of increasing mechanization on the larger farms into account, one is, in our view, justified in forecasting a $25 \%$ decrease in the numbers employed in agriculture in the six countries of the European Economic Community. We would even put the corresponding figure for the countries of Eastern and Southern Europe higher. Expressed in numbers, this comes to almost 3 million males employed in agriculture for the six E.E.C.-countries and to 9 to 10 million for Europe as a whole.

It may be remarked further in this connection that in various countries of Europe, the post-war trend has been towards increasing mechanization, a reduction in the number of small farms and a resultant decrease in the numbers employed in agriculture. Thus our estimates for 1973 link up with a natural process already underway. In the Netherlands, for example, employment in agriculture has been decreasing during the last ten years by $1 \frac{1}{2}$ to $2 \%$ per annum. Should this trend continue during the next fifteen years, this, too, would result in the same reduction of about $25 \%$ by the end of that period.

\section{The EFFLUX OF YOUNGER AGE-GROUPS FROM AGRICULTURE}

It is against the background that has been very briefly sketched in the foregoing paragraphs that we must consider the question of the efflux of younger workers from the agricultural sector, for it goes without saying that the volume of the primary outflow of these younger workers to non-agricultural branches of industry should be closely correlated to the volume of population it is desired to see employed in farming in the future.

But quite apart from any future decline in this group, it is necessary for other reasons too that many young people belonging to farming families should choose a job outside agriculture. The number of these youths reaching the employable age every year is, as a matter of fact, much greater than the number of persons who leave farming every year. Figures relating to this point will be found in table 2. It will be seen from these figures that about $50 \%$ of the boys upto the age of 14 coming from farming families will have to choose a job outside agriculture. This means that in the next fifteen years more than two million of these young people in the six E.E.C.-countries will have to find their way to other occupations. This percentage will have to be still higher for the East-European countries, but can be lower for some countries in Northwestern Europe. For Europe as a whole, the total figure for the next fifteen years can be put at eight million. 
The facts indicate that this draining-off of labour from agriculture is taking place on an insufficient scale. Experience has shown, moreover, that it takes place far too late in the lifetime of the persons concerned. Many young farming people only arrive at the conviction that there is no room for them in farming when they are getting on in years. This should constitute no cause for surprise in our opinion, for the numbers involved here are not small. It would be far more a cause of surprise if the stream of youths leaving the farming sector for non-agricultural occupations every year - a large proportion of them also leaving the countryside for the town - were to be large enough. In countries undergoing economic development, farming is, after all, a declining industry, that is to say, every year more than the surplus of births over deaths must leave it for other branches of industry.

It need hardly be said that the inadequate rate of efflux is no very attractive matter for those concerned nor has it a favourable effect on the general level of welfare. But a highly important factor for these young people, besides the need for adequate numbers of them to leave farming in good time, is that they should be able to secure reasonably good jobs in the other branches of industry. This calls for good and suitably-planned vocational training. As yet, however, we have insufficient knowledge of the whole process of the outflow of labour from agriculture. More facts and more understanding of the problem are required in order for us to be able to take the appropriate measures.

In the Netherlands extensive research work has been done into the various aspects of this matter, and some of the most important information will soon be published. It will be seen from these information that the efflux is insufficient and comes too late; moreover show the figures that many sons of farmers (outside agriculture) have got an inadequate training or no training at all and choosed an unskilled profession.

\section{What CAN BE DONE}

We are faced with the question of how this highly desirable efflux of younger people from farming can be fostered and directed into the right channels. In our view, the most appropriate way would be to provide the rural population with advice and information about the choice of schools and occupations; information, that is, about the jobs there are to be chosen. It is important in this connection that the persons having to make this choice should be tested to find out for which job they are best fitted. The supply of information on training facilities for the various occupations concerned would then follow automatically. It is remarkable - to put it mildly - that one of the most important decisions a man or woman can make in life - the choice of an occupation - should be taken by the large majority of people with so little knowledge of the matter. The setting-up of a sufficient number of bureaux for providing advice on the choice of schools and occupations is consequently the least one can do to see that adequate numbers of young people in the rural areas choose jobs outside agriculture. Apart from emigration, one of the conditions for this will, of course, be the expansion of employment opportunities in non-agricultural industries.

In many countries there is no information service of any kind on this subject, and in those where there is, it is confined mainly to the large towns. 
Insufficient attention has been paid to this matter during the last one hundred and fifty years during which Europe has gone through enormous economic development. The large-scale migration from the countryside to the towns that has taken place during this period has been left unregulated, to sort itself out itself, without doubt to the disadvantage of both town and country. It would have been of great importance that sufficient economic, and especially sufficient social, advice and information should have been given in addition to technical advice and information. And not only advice - but education too. Social and economic advice and information must also be based, of course, on research, just as technical advice and information (and education) are. A number of incidental inquiries into the draining-off of farm labour, the small farmer problem, the agricultural labourer problem, the village problem etc., have been made from time to time in some countries, but in our view far more research is required to enable us to guide the further development of farming in Europe into the right channels.

Perhaps the countries which are still in the initial stages of such development will be able to derive a lesson from this - here we are thinking primarily of the countries of Southern and Eastern Europe. With more than $50 \%$ of the working population employed in agriculture and with comparatively low standards of living, these countries have still a long way to go before they reach the level of welfare prevailing in Western Europe and other economically-developed countries. It would be an excellent thing if these countries were to benefit from the experience gained during the course of Western Europe's economic development.

It is clear - as was already pointed out in the introductory section - that the gradual draining-off of younger people from agriculture cannot exist by itself, in isolation. An efflux of adequate volume and a reduction in the total number of persons employed in agriculture can only take place if accompanied by simultaneous mechanization and the rationalization of farming. But in order to transform the possibilities of mechanization and the reduction of the labour force employed in agriculture into actual fact, the farming population will have to be ready to accept a wholesale modernization of the agrarian structure and its adaption to the present state of technical development. As far as modernization is concerned, we have primarily in mind the enlargement of the farms, improved parcelling of land and the re-siting of farm buildings. In order to ensure that the farming population utilizes these new opportunities to the full, great attention will, of course, have to be paid to teaching, to the supply of advice and information and to education.

One further question demands our attention. What will happen to the countryside after these drastic changes in the structure of farming, accompanied by a fairly considerable decrease in the farming population, have come about? Will not the countryside become depopulated and experience the same fate as some areas in France and England? In our view, this need not be the case, provided the countryside is not forgotten when plans for further industrialization are drawn up. We are of the opinion that the decentralization of industry is one of the first requirements for Europe's further economic development, in order to see that the countryside does not become depopulated. Of course no industrialisation over the whole countryside, but in certain centres; however it must be able that these centres can be reached 
by the commuters who lives in the villages. For the rest, we shall have to be prepared, of course, to modernize the countryside's tools and equipment. Attention will have to be paid to development, to public transport, public utilities; the housing situation, schools and cultural amenities. Provided, therefore, that thought is given to a re-distribution if industry over regional centres and to the modernization of the countryside's equipment, structural changes in agriculture need not, in our opinion, lead to the depopulation of rural areas. 